SECTION 7. Mechanics and machine construction.

Tlebayev Manat Beyshenovich Doctor of engineering sciences, Professor, Academician of Kazakh National Academy of Natural Sciences, Head of the department «Computer engineering and Informatics» Taraz State University named after M.Kh. Dulati, Kazakhstan

Shevtsov Pavel Nikolayevich student

Taraz State University named after M.Kh. Dulati, Kazakhstan pasha369@mail.ru

\title{
COMPUTER MODEL OF THE EXTRUSION PROCESS
}

Abstract: the Development of technologies for production of orthotropic materials requires continuous improvement extrusion devices. Actual development of mathematical models of mixing and research at all stages of the technological process of manufacture of building products.

Key words: orthotropic material, extrusion, filler, mathematical model.

\section{ОБ ОДНОЙ КОМПЬЮТЕРНОЙ МОДЕЛИ ПРОЦЕССА ЭКСТРУЗИИ}

Аннотация: Развитие технологий производства ортотропных материалов требует непрерывного совершенствования аппаратов экструзии. Актуальна разработка математических моделей смешивания компонентов и проведение исследований на всех технологических этапах изготовления строительной продукиии.

Ключевые слова: ортотропный материал, экструзия, наполнитель, математическая модель.

Процесс экструзии непосредственно связан, и делится на два технологических момента: смешивания стекловолокна с полимерным наполнителем и процессом выдавливания его в определенную форму (заготовку). Здесь необходимо учитывать не только строго заданную температуру, во избежания излишней текучести образца после экструзии, но и достижение жидкого состояния для равномерного смешивания компонентов и обеспечение заданной плотности образца.

Примерами подобных моделей могут являться модели горячей экструзии (рис.1). А для их реализации наиболее подходят конечноэлементные методы моделирования [1]. При построении модели также учитывают точность расчетов (рис.2-3). Рассмотренные модели являются осесимметричными и могут быть решены как вплоской постановке, так и в трехмерной.

Рассмотрим процесс горячей экструзии ортотропного вещества на основе рубленного стокловолоконного роувинга и полимерного связующего. При этом однородная модель полимера будет иметь равномерные вкрапления стеклянных нитей, расположенные случайным образом и изогнутые в произволных направлениях. Для простоты будем рассматривать плоскую осесимметричную модель.

После того, как построена модель, построим ее конечно-элементный аналог (сетка узлов и элементов). Как известно [3] существует более 80 типов сеток, каждый из которых определяет, среди прочего, применимость элемента к той или иной области расчетов (прочностной, тепловой, магнитный и электрический анализы, движение 
жидкости или связанные задачи), характерную форму элемента (линейную, плоскую, в виде бруска и т. д.), а также двумерность (2-D) или трехмерность (3-D) элемента.
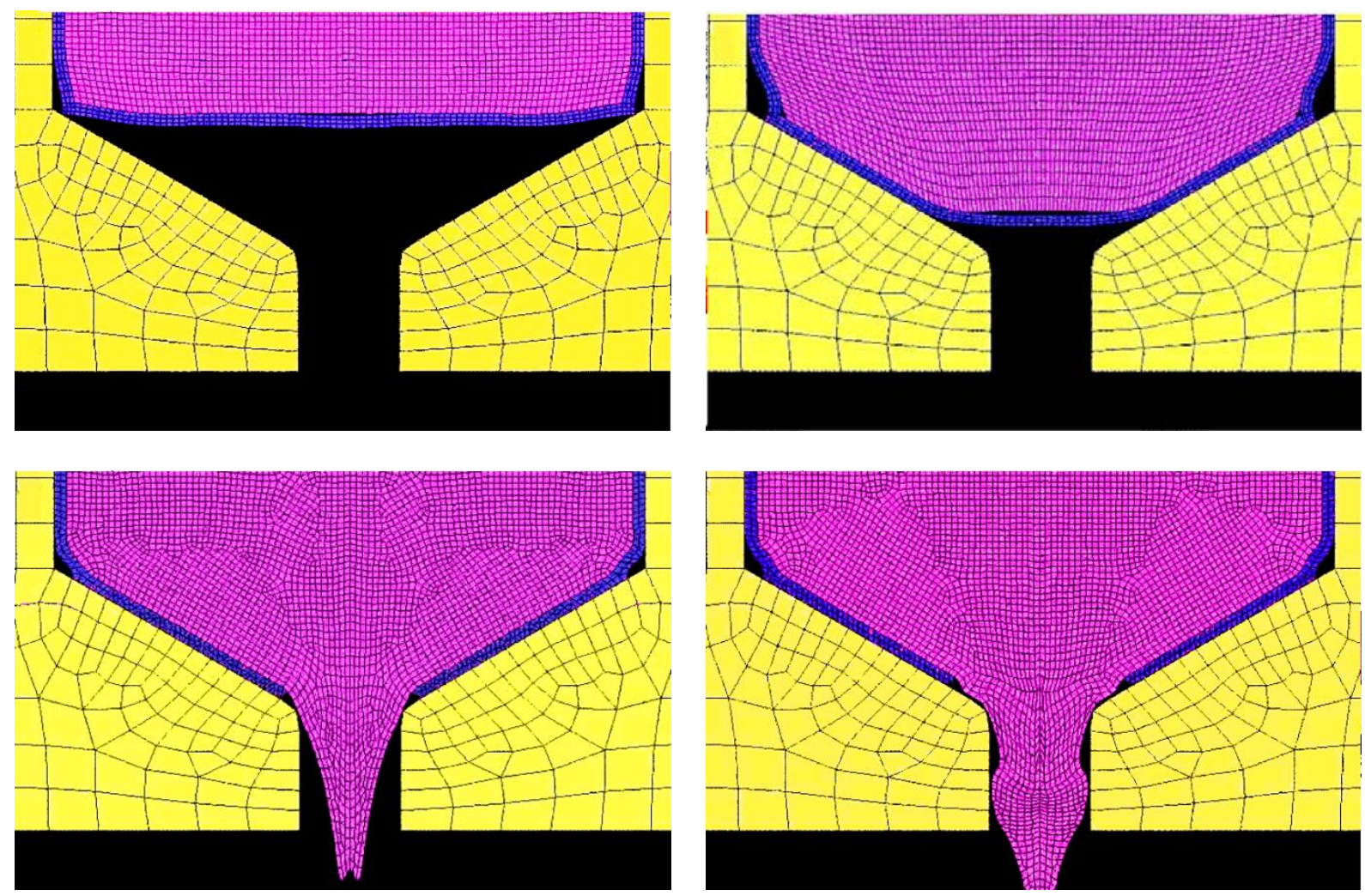

Рисунок 1 - Моделирование процесса горячей экструзии [1].
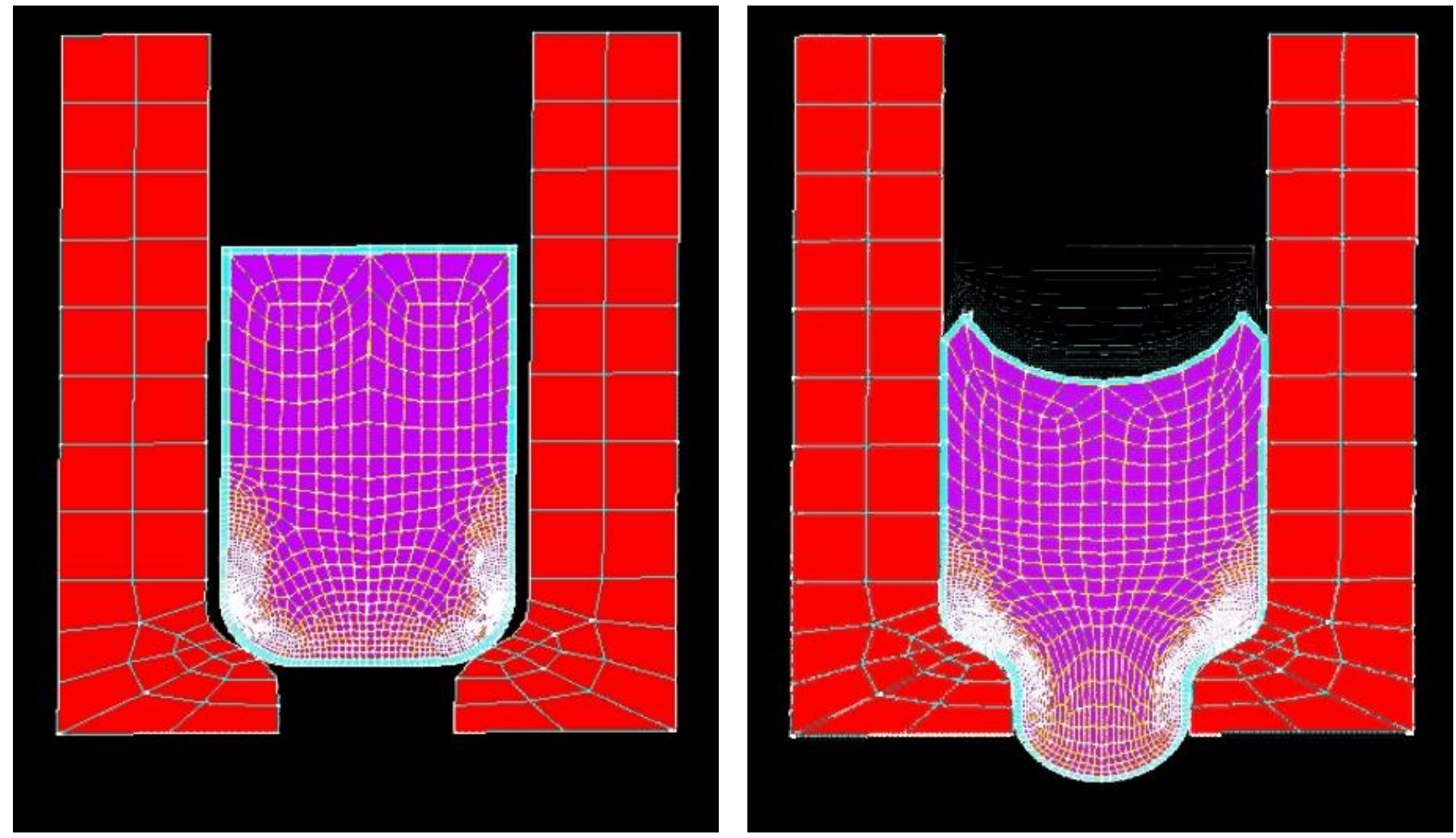

Рисунок 2 - Моделирование процесса горячей экструзии с повышенной точностью расчетов [2]. 

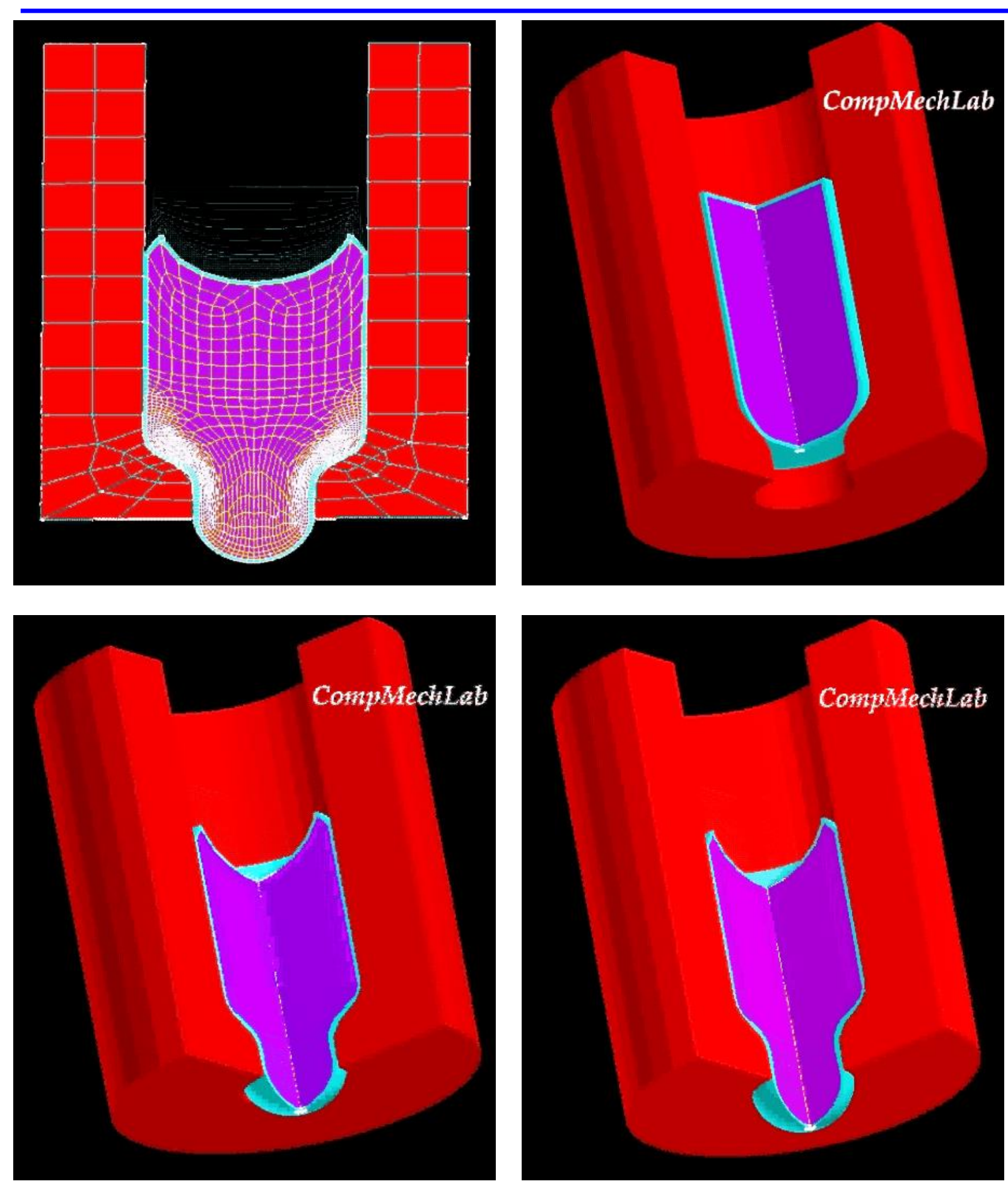

\section{Рисунок 3 - Трехмерное моделирование процесса горячей экструзии с повышенной точностью расчетов [2].}

После выбора типа элементов необходимо задать их константы. Константы элемента - это свойства, специфичные для данного типа элемента. Например, для элемента оболочки экструзионной камеры все элементы будем считать неподвижными.

Задание свойств материалов. В нашей постановке задачи их три. Свойства материала требуются для двух типов элементов. В зависимости от области приложения свойства могут быть линейными, нелинейными и (или) анизотропными.

Линейные свойства могут зависеть или не зависеть от температуры, быть изотропными или ортотропными. Зависимость свойств от температуры имеет форму полинома (вплоть до четвертой степени) или задается таблично.[3] 
Нелинейные соотношения, такие как кривые деформирования и кривые ползучести, для нашей задачи будем задавать в виде таблицы.

Рассмотрим способ генерации сетки для метода экструзии.

\section{Метод экструзии.}

Метод экструзии (выдавливания) используется для превращения областей двумерной сетки в трехмерные объекты, состоящие из параллелепипедов, клиновидных элементов или их комбинации [3]. Процесс экструзии осуществляется с помощью процедур смещения из плоскости, буксировки, поступательного и вращательного перемещений (рис.4). Технологический процесс экструзии складывается из последовательного перемещения материала вращающимся шнеком в его зонах (см. рис. 1): питания (I), пластикации (II), дозирования расплава (III), а затем продвижения расплава в каналах формующей головки [9-10].

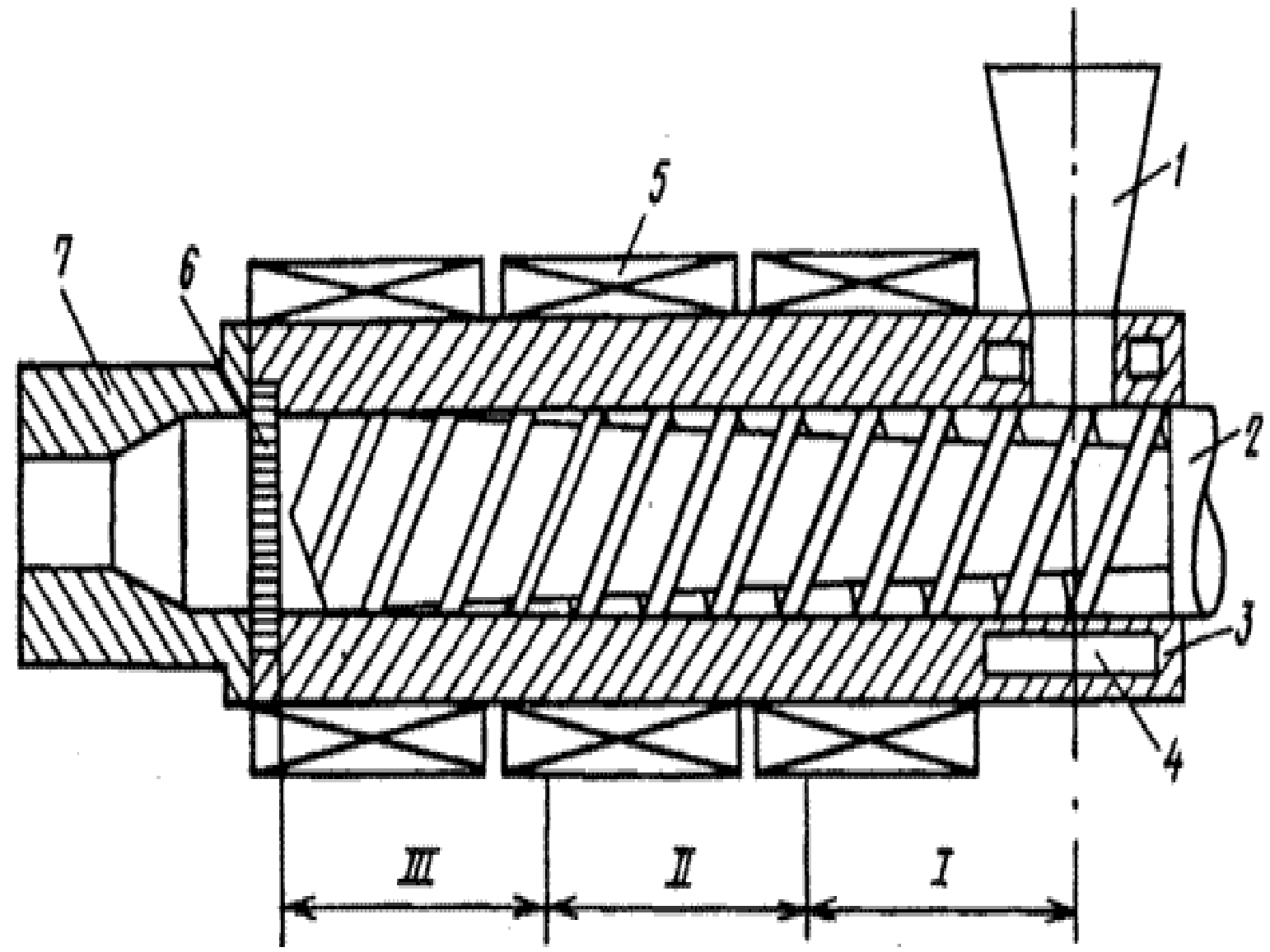

Рисунок 4 - Схема одношнекового экструдера [10]

1- бункер; 2- шнек; 3- цилиндр; 4- полость для циркуляции воды;

5- нагреватель; 6- решетка с сетками; 7- формующая головка.

Поведение полимера внутри экструдера рассмотрим на примере одношнековой экструзии гранулированного материала [11]. Технологический процесс экструзии складывается из последовательной пластикации и перемещения материала вращающимся шнеком в зонах материального цилиндра.

Можно сказать, что деление шнека на зоны I-III достаточно условно, оно осуществляется по технологическому признаку и указывает на то, какую операцию в основном выполняет данный участок шнека [11]. Цилиндр также имеет определенные длины зон обогрева. Длина этих зон определяется расположением нагревателей на его поверхности и их температурой. Границы зон шнека I-III и зон обогрева цилиндра 
могут не совпадать. Для обеспечения успешного перемещения материала большое значение имеют условия продвижения твердого материала из загрузочного бункера и заполнение межвиткового пространства, находящегося под воронкой бункера.

Полимерный материал для экструзии, подаваемое в бункер, может быть в виде порошка, гранул, лент [11]. Наиболее часто экструзией перерабатываются гранулированные пластики. Переработка полимера в виде гранул - оптимальный вариант питания экструдера. Гранулы полимера меньше склонны к "зависанию" и образованию пробок в бункере, чем порошок, а также гранулы легче пластицируются и гомогенизируются. Загрузка межвиткового пространства щнека под воронкой бункера происходит на отрезке длины шнека, равном (1-1,5)D. При переработке многокомпонентных материалов для загрузки их в бункер применяются индивидуальные дозаторы: шнековые (объемные), вибрационные, весовые и т.п. Сыпучесть материала сильно зависит от его влажности: чем больше влажность, тем меньше сыпучесть. Поэтому гигроскопичные материалы необходимо сушить перед загрузкой

Применяя приспособления для принудительной подачи материала из бункера в материальный цилиндр, также удается существенно повысить производительность машины. При уплотнении материала в межвитковом пространстве шнека вытесненный воздух выходит обратно через бункер. Если удаление воздуха будет неполным, то он останется в расплаве и после прохождения через головку образует в изделии нежелательные полости.

При длительной работе экструдера возможен перегрев цилиндра под воронкой бункера и самого бункера. В этом случае гранулы начнут слипаться и прекратится их подача на шнек. Для предотвращения перегрева этой части цилиндра в нем делаются полости для циркуляции охлаждающей воды. Обычно зона загрузки является единственной охлаждаемой зоной современных экструдеров.

1. Зона питания (I). Поступающие из бункера гранулы или порошок полимера заполняет межвитковое пространство шнека зоны I и уплотняется.

2. Зона пластикации и плавления (II). В зоне II происходит подплавление полимера, примыкающего к поверхности цилиндра. В тонком слое расплава полимера происходят интенсивные сдвиговые деформации, как следствие материал пластицируется, что приводит к интенсивному смесительному эффекту.

Основной подъем давления Р расплава происходит на границе зон I и II. На этой границе образующаяся пробка из спрессованного материала как бы скользит по шнеку: в зоне I это твердый материал, в зоне II- плавящийся. Наличие этой пробки и создает основной вклад в повышение давления расплава. Запасенное на выходе из цилиндра давление расходуется на преодоление сопротивления сеток, течения расплава в каналах головки и формования экструдируемого профиля [11].

3. Зона дозирования (III). Расплавленная масса полимера продолжает гомогенизироваться, однако она все еще не является однофазной и состоит из расплавленных и твердых частиц. В конце зоны III пластик становится полностью гомогенным и готовым к продавливанию через чистящие сетки и формующую головку.

\section{Основные параметры процесса экструзии}

К технологическим параметрам переработки пластмасс методом экструзии относятся: температура по зонам экструдера давление расплава, 
температура зон головки

режимы охлаждения экструдированного профиля

Основными технологическими характеристиками экструдера являются длина шнека L, диаметр шнека $\mathrm{D}$, соотношение $\mathrm{L} / \mathrm{D}$, скорость вращения шнека $\mathrm{N}$, а также профиль шнека и степень изменения объема канала шнека.

Основной характеристикой формующего инструмента, состоящего как правило из экструзионной головки (вместе с фильтрующими сетками) и калибрующего узла, является коэффициент сопротивления течению расплава К. Перепад давления на фильтрующих сетках служит показателем засорения, т. е. увеличения сопротивления сеток и, следовательно, сигналом к их замене.

Непосредственное создание компьютерной модели будем осуществлять в Delphi c применением DirectX и OpenGL. При использовании этого подхода конечноэлементную модель можно построить, определив положение каждого узла, а также размеры форму и связность для всех элементов сетки. Узлы используются для того, чтобы определить положение элементов в пространстве, а элементы определяют связность модели. И те, и другие можно задавать нам более удобным способом, не заботясь об эффективности решения.

После создания модели и задания граничных условий программа генерирует конечно элементную сетку, выполняет расчет, оценивает ошибку за счет сеточной дискретизации и меняет размер сетки от решения к решению до тех пор, пока расчетная погрешность не станет меньше некоторой наперед заданной величины [3].

Приложение нагрузок

Под действующими нагрузками будем понимать как внешние и внутренние усилия, так и граничные условия в виде ограничений на перемещения. Разделим нагрузки на следующие категории:

- ограничения степеней свободы;

- сосредоточенные силы; (отсутствуют)

- поверхностные нагрузки;

- объемные силы;

- инерционные нагрузки. (отсутствуют)

Большинство этих нагрузок может быть приложено или к твердотельной модели (в ключевых точках, по линиям и поверхностям), или к конечно-элементной модели (в узлах и к элементам) [3]. Также полную последовательность нагрузок можно разбить на несколько шагов нагружения.

Шаг решения - это изменение счетного шага внутри шага нагружения; используется главным образом при нестационарном и нелинейном анализе для улучшения точности и сходимости. Шаг решения также называют шагом по времени, т. е. шагом, выполняемым в течение некоторого промежутка времени.

При решении время будет использоваться как указатель на тот или иной шаг нагружения или шаг решения.

Для указания допустимых пределов изменения степеней свободы в узлах модели будем использовать - ограничения смещения узлов оболочки и стеклянных волокон. Ограничения степеней свободы, заданные на твердотельной модели, автоматически передаются программой в сеточную модель при инициализации процедуры численного решения. Также необходимо задать свойства нитей стекловолокна и связующего[4-8]. При этом растяжение волокн можно принять равным нулю, а вот изгиб придется учитывать и расчитывать для каждой отдельной нити. 
После того, как все соответствующие параметры заданы, может быть выполнено и само решение. Результаты будем записывать в специальный файл - базу данных. При этом в базе данных будут храниться результаты для всех шагов решения. Программой будет выполняться решение определяющих уравнений и получение результатов.

\section{Литература}

1. Моделирование процесса горячей экструзии титановых брикетов. LS-DYNA (2003 г.) [Электронный $\quad$ pecypc] $\underline{\text { http://www.fea.ru/AVIGallery_LS- }}$ DYNA Titanium Briquettes_Extrusion_13.html (Дата доступа 17.02.2014).

2. Моделирование процесса горячей экструзии прессованной титановой стружки в стальной капсуле (2003 г.) [Электронный pecypc] http://www.fea.ru/AVIGallery_ANSYS Titanium_Briquettes_Extrusion_12.html (Дата доступа 17.02.2014).

3. Методические указания по Ansys 6.1. [Электронный ресурс] http://www.myref.ru/preview/43459.html (Дата доступа 17.02.2014).

4. Мищенко С.В., Дмитриев А.О., Дмитриев С.О. Метод и устройство для определения реологических характеристик связующего в процессе отверждения полимерных композитов. Теплофизические исследования и измерения в энергосбережении, при контроле, управлении и улучшении качества продукции, процессов и услуг : материалы Седьмой международной теплофизической школы : в 2 ч. Тамбов, $20-25$ сент. 2010 г. / ГОУ ВПО ТГТУ. - Тамбов, 2010. - Ч. II. С. 129 - 131.

5. Мищенко С.В. Методология выбора оптимальных режимных параметров методов и рациональных конструкционных размеров устройств для измерения теплофизических свойств веществ, материалов и изделий / С.В. Мищенко, С.В. Пономарев // Теплофизические исследования и измерения в энергосбережении, при контроле, управлении и улучшении качества продукции, процессов и услуг : материалы Седьмой международной теплофизической школы : в 2 ч. Тамбов, $20-25$ сент. 2010 г. / ГОУ ВПО ТГТУ. - Тамбов, 2010. - Ч. І. - С. 54 - 60.

6. Алексеев К.П., Каюмов Р.А., Мухамедова И.З., Терегулов И.Г Экспериментальное исследование ползучести композиционных материалов на трубчатых образцах из органопластика. Механика композиционных материалов и конструкций. 2004 г., том 10, №2.

7. Олейников А.И. Модели анизотропной ползучести. - II Всероссийская конференция "Деформирование и разрушение структурно-неоднородных сред и конструкций", посвященная 85-летию со дня рождения профессора О.В. Соснина. -10-14 октября 2011 г., Новосибирск, Россия

8. Касатонов И.С., Дмитриев О.С. Автоматизированная система контроля процесса отверждения полимерных композиционных материалов// Теплофизические измерения в начале XXI века: Тез. докл IX Международной теплофизической школы.- Тамбов: Из-во ТГТУ, 2001.

9. Экструзионные линии. [Электронный ресурс] http://pic-polimer.ru/ekstryderiy.htm (Дата доступа 20.02.2014).

10. Описание и технологии переработки - Экструзия. [Электронный ресурс] http://www.polymerbranch.com/termoplast/view/5.html (Дата доступа 20.02.2014).

11. Экструзия. [Электронный pecypc] http://www.e-plastic.ru/specialistam/extrusion (Дата доступа 20.02.2014). 